\title{
Photocoagulation in proliferative sickle retinopathy: results of a 5-year study
}

\author{
PATRICK I. CONDON AND GRAHAM R. SERJEANT \\ From the Medical Research Council Laboratories, University of the West Indies, \\ Kingston, Jamaica
}

SUMMARY The progress of proliferative sickle retinopathy (PSR) in 57 eyes treated by xenon arc photocoagulation has been compared with that in 41 comparison eyes. Angiographic assessment of the treated PSR lesions in 54 patients followed up for a mean period of 47 months (range 8-65 months) revealed cessation of leakage in $44(81 \%)$, reduction of leakage in $8(15 \%)$, and no change in $2(4 \%)$. In the 41 comparison eyes more extensive perfused PSR occurred in $25(60 \%)$, no change in $8(20)$, and spontaneous improvement in $8(20 \%)$. Autoinfarction of PSR lesions in comparison eyes was observed during the study period in $16(39 \%)$. Assessed by visual acuity, there was no significant difference between treatment and comparison groups, deterioration of 3 lines or more on the Snellen chart occurring in $9 \%$ of the treated eyes and $5 \%$ of the comparison eyes. Vitreous haemorrhages occurred in $8(14 \%)$ of treated eyes and in $7(17 \%)$ of the comparison group. The most common complication of photocoagulation was choroidal neovascularisation in the burn area, choroidoretinal neovascularisation (CRN) occurring in 19 patients and choroidovitreal neovascularisation (CVN) in 12 patients. In 4 of the latter patients CVN lesions underwent rapid growth and in 4 were associated with vitreous haemorrhages. Other complications in the treated eyes included transient partial third nerve palsies, preretinal haemorrhage, haemorrhage confined to the burn area, vitreous haemorrhage, vitreoretinal traction, and retinal detachment. Statistical limitations of the present study dictate that the results be interpreted with caution. However, the complications of therapy, and the high prevalence of autoinfarction in the comparison eyes, indicate the need for a properly randomised study to define the role, if any, of photocoagulation in the therapy of proliferative sickle retinopathy.

Peripheral retinal capillary occlusion in sickle cell disease initiates a sequence of vascular events that may culminate in proliferative sickle retinopathy (PSR). Arising from arteriovenous anastomoses at the border of ischaemic retina, arcades of abnormal vessels grow out along the retina or project into the vitreous. As these arcades proliferate, they carry larger blood flows and are supplied by enlarged feeding arterioles and draining venules. These abnormal vessel systems leak fluorescein and plasma and may give rise to vitreous haemorrhage and either traction or rhegmatogenous retinal detachment. The risks of transient or permanent visual impairment have prompted attempts to render these lesions avascular by occluding the feeding arterioles

Correspondence to Dr Graham R. Serjeant, Medical Research Council Laboratories, University of the West Indies, Kingston, Jamaica. with xenon photocoagulation, ${ }^{1-3}$ argon laser photocoagulation, ${ }^{3-5}$ diathermy, ${ }^{2}$ and cryopexy. $^{6}$ The techniques and preliminary results of xenon light coagulation in a group of Jamaican patients were reported by Condon and Serjeant, ${ }^{2}$ and the results in a 5-year follow-up of this group are now presented.

\section{Patients and methods}

Patients were selected from the sickle cell clinic of the University Hospital of the West Indies. Of the 37 patients originally admitted to the study ${ }^{2} 33$ have been followed up for periods between 30 and 65 months, the remaining 4 patients having defaulted (2) or emigrated (2). Seven patients were added to the study in March 1974, 5 in December 1974, 6 in August 1975, and 6 in January 1977, bringing the total of patients to 57. At the last review, in July 832 
1978, patient follow-up varied from 8 to 65 months with a mean of 47.0 months.

There were 8 patients with homozygous sickle cell (SS) disease, 43 with sickle cell-haemoglobin C (SC) disease, 4 with sickle cell- $\beta^{+}$thalassaemia $\left(\mathrm{S} \beta^{+}\right.$thalassaemia) and 2 with sickle cell- $\beta^{\circ}$ thalassaemia ( $\left(\beta^{\circ}\right.$ thalassaemia). There were 33 males and 24 females with ages ranging from 13 to 64 years on admission to the study. The criteria used for haematological diagnosis were described by Serjeant ${ }^{7}$ and involved haemoglobin electrophoresis under alkaline and acid conditions, and quantitation of $\mathrm{HbA}_{2}$ to differentiate SS disease from $S \beta^{\circ}$ thalassaemia.

Proliferative sickle retinopathy (PSR) was present on admission to the study or developed during the study bilaterally in 47 and unilaterally in 10 of the 57 patients. All eyes were treated in patients with unilateral involvement. In those with bilateral involvement the worst affected eye was treated in 41 patients and the less affected eye in 6 patients, in whom visual acuity in the worst eye was $<6 / 60$. The remaining 47 eyes in patients with bilateral involvement were followed up as a comparison group. Ophthalmological assessments as previously described $^{\mathbf{3}}$ were made during short-term visits (usually 3 weeks) at approximately yearly intervals by the visiting ophthalmologist (P.I.C.). Techniques of xenon arc photocoagulation using the O'Malley log. II photocoagulator included closure of the feeding arteriole and direct coagulation of the PSR lesion. ${ }^{2}$ The draining venule was not directly coagulated. Retrobulbar anaesthesia was induced by injecting $2 \%$ xylocaine without epinephrine through a sharp $50 \mathrm{~mm} 25 \mathrm{~g}$ retrobulbar needle. The volume of local anaesthetic was routinely $3.5 \mathrm{ml}$, but variability in anaesthetic quality occasionally necessitated a volume of 5-6 $\mathrm{ml}$ for adequate anaesthesia.

The results of treatment were assessed by changes in dye leakage from the treated lesions, changes in visual acuity, and by comparing complications in the treatment and comparison eyes. Post coagulation angiographic assessments were generally performed 4-7 days after treatment.

\section{Results}

A total of 220 PSR lesions in the 57 patients were treated by xenon photocoagulation supplemented by diathermy in 8 patients. These included 33 lesions in SS disease (4.1 lesions/patient), 169 in SC disease (3.9 lesions/patient), 10 in $\mathrm{S} \beta^{+}$thal ( 2.5 lesions/patient), and $8 \mathrm{~S} \beta^{\circ}$ thal $(4.0$ lesions/ patient). The results in terms of fluorescein leakage from the treated PSR and complications of therapy

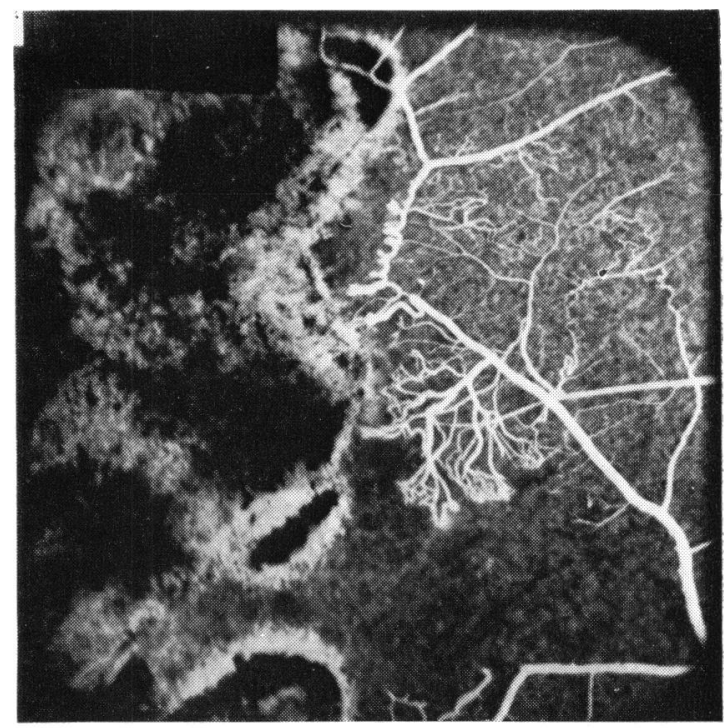

Fig. 1 Fluorescein angiogram of right temporal area in a 17-year-old female with SC disease (case 12) showing PSR lesion developing proximal to photocoagulation burn I year earlier.

are summarised in Table 1 and the visual acuities at the beginning and end of the study in Table 2 .

LEAKAGE FROM PROLIFERATIVE LESIONS Closure of feeding vessels and cessation of fluorescein leakage from the treated PSR lesions was achieved by one (41 patients) or more (5 patients) treatment sessions in $46 / 53(87 \%)$ patients in whom post-therapy angiograms (4-7 days after treatment) were available. Leakage continued despite repeated coagulation in 4 patients (cases $26,38,42,43$ ), and additional therapy was not attempted in 3 patients (cases 7, 30, 41). After successful initial closure fluorescein leakage from retinal lesions recurred in 8 patients, being attributed to reperfusion of the original PSR lesion in 3 patients (cases 8, 16, 51) and to the development of new PSR lesions (Fig. 1) in 5 patients (cases 12, 15, 19, 31, 57). Further treatment of reperfused lesions was unsuccessfully attempted in 2 patients and not attempted in 1, and treatment of new PSR lesions was successful in the 3 patients in which it was attempted. In 2 patients (cases 34, 47) the extreme peripheral location of small PSR lesions did not allow attempted closure by the photocoagulator in use, but other lesions in both patients were satisfactorily occluded.

Fluorescein angiographic assessment at the end of study periods varying from 8 to 65 months (mean 47 months) was performed in all patients except 2 developing retinal detachment (cases 26 . 
Table 1 Clinical details, response to therapy, and complications in treatment group

\begin{tabular}{|c|c|c|c|c|c|c|c|}
\hline $\begin{array}{l}\text { Series } \\
\text { cases }\end{array}$ & $\begin{array}{l}\text { Age } \\
\operatorname{sex}\end{array}$ & $\begin{array}{l}\text { Eye } \\
\text { treated }\end{array}$ & $\begin{array}{l}\text { Number } \\
\text { PSR lesions } \\
\text { treated } \\
(D=\text { diathermy })\end{array}$ & $\begin{array}{l}\text { Duration of } \\
\text { follow up } \\
\text { (months) }\end{array}$ & $\begin{array}{l}\text { Final } \\
\text { assessment } \\
\text { leakage from } \\
\text { treated PSR }\end{array}$ & $\begin{array}{l}\text { Complications } \\
\text { treated eye }\end{array}$ & $\begin{array}{l}\text { Case in } \\
\text { previous } \\
\text { series }^{2}\end{array}$ \\
\hline \multicolumn{8}{|c|}{ Homozygous sickle cell disease } \\
\hline $\begin{array}{l}1 \\
2 \\
3 \\
4 \\
5 \\
6 \\
7 \\
8\end{array}$ & $\begin{array}{ll}20 & \mathrm{M} \\
31 & \mathrm{M} \\
34 & \mathrm{~F} \\
36 & \mathrm{M} \\
48 & \mathrm{M} \\
49 & \mathrm{M} \\
56 & \mathrm{~F} \\
57 & \mathrm{~F}\end{array}$ & $\begin{array}{l}\mathbf{L} \\
\mathbf{L} \\
\mathbf{R} \\
\mathbf{L} \\
\mathbf{R} \\
\mathbf{L} \\
\mathbf{R} \\
\mathbf{R}\end{array}$ & $\begin{array}{l}3 \\
4 \\
1 \\
3 \\
9 \\
1 \text { (D) } \\
5 \\
7 \text { (D) }\end{array}$ & $\begin{array}{l}46 \\
44 \\
65 \\
19 \\
44 \\
44 \\
8 \\
65\end{array}$ & $\begin{array}{l}\text { Ceased } \\
\text { Ceased } \\
\text { Ceased } \\
\text { Ceased } \\
\text { Ceased } \\
\text { Ceased } \\
\text { No change } \\
\text { Improved }\end{array}$ & $\begin{array}{l}\text { PVD, CRN } \\
\text { Nil } \\
\text { Nil } \\
\text { Nil } \\
\text { VRT } \\
\text { Nil } \\
\text { Nil } \\
\text { AU, VH, PVD, RT }\end{array}$ & $\begin{array}{l}\frac{44}{34} \\
\frac{-}{-} \\
\frac{-}{13}\end{array}$ \\
\hline
\end{tabular}

Sickle cell-haemoglobin C disease

\begin{tabular}{|c|c|c|c|c|c|c|c|}
\hline 9 & $13 \mathrm{~F}$ & $\mathbf{R}$ & 3 & 46 & Ceased & Nil & 29 \\
\hline 10 & $14 \mathrm{M}$ & $\mathbf{R}$ & 1 & 46 & Ceased & $\mathrm{VH}, \mathrm{CVN}$ & 14 \\
\hline 11 & $15 \mathrm{M}$ & $\mathbf{L}$ & 1 (D) & 46 & Ceased & 3NP, AU, PRH, VH (2), VRT, CVN & 8 \\
\hline 12 & $16 \mathrm{~F}$ & $\mathbf{R}$ & 5 & 65 & Ceased & RHB (2), CRN & 15 \\
\hline 13 & $18 \mathrm{M}$ & $\mathbf{L}$ & 1 & 29 & Ceased & CRN & 25 \\
\hline 14 & $18 \mathrm{M}$ & $\mathbf{L}$ & 2 & 65 & Ceased & RHB (2), CRN & 28 \\
\hline 15 & $18 \mathrm{~F}$ & $\mathbf{R}$ & 1 & 36 & Unknown & Nil & - \\
\hline 16 & $18 \mathrm{~F}$ & $\mathbf{R}$ & 6 (D) & 53 & Improved & Nil & - \\
\hline 17 & $21 \mathrm{M}$ & $\mathbf{L}$ & 1 & 65 & Ceased & CRN & 20 \\
\hline 18 & $21 \mathrm{~F}$ & $\vec{L}$ & 2 & 19 & Ceased & 3NP, CRN & - \\
\hline 19 & $22 \mathrm{M}$ & $\mathbf{L}$ & 1 & 19 & Ceased & RHB, VH, CVN & - \\
\hline 20 & $23 \mathrm{M}$ & $\mathbf{L}$ & 6 (D) & 65 & Ceased & AU, PRH (4), CRN & 10 \\
\hline 21 & $23 \mathrm{M}$ & $\mathbf{R}$ & 7 & 65 & Ceased & RHB (2) & 27 \\
\hline 22 & $24 \mathrm{~F}$ & $\mathbf{L}$ & 4 & 29 & Ceased & PVD, ERM, CVN & 36 \\
\hline 23 & $24 \mathrm{~F}$ & $\mathbf{R}$ & 3 & 19 & Ceased & CRN (2) & - \\
\hline 24 & $25 \mathrm{~F}$ & $\mathbf{R}$ & 6 (D) & 65 & Ceased & ASI, PRH (4) & 9 \\
\hline 25 & $25 \mathrm{M}$ & $\mathbf{R}$ & 3 & 29 & Ceased & CRN & 17 \\
\hline 26 & $26 M$ & $\mathbf{R}$ & 7 & 46 & Unknown & RD, VH & 42 \\
\hline 27 & $27 \mathrm{~F}$ & $\mathbf{R}$ & 4 & 34 & Ceased & RHB, CRN (2) & - \\
\hline 28 & $28 \mathrm{M}$ & $\mathbf{L}$ & 3 & 36 & Ceased & CVN & - \\
\hline 29 & $28 \mathrm{M}$ & $\mathbf{R}$ & $5(\mathrm{D})$ & 65 & Ceased & VH, ?CRN & 11 \\
\hline 30 & $28 \mathrm{~F}$ & $\mathbf{L}$ & 10 & 19 & Improved & Nil & - \\
\hline 31 & $28 \mathrm{~F}$ & $\mathbf{L}$ & 2 & 46 & Ceased & CRN & 26 \\
\hline 32 & $29 M$ & $\overrightarrow{\mathbf{L}}$ & 5 & 65 & Ceased & RHB & 16 \\
\hline 33 & $29 \mathrm{~F}$ & $\mathbf{R}$ & 2 & 53 & Ceased & CVN & - \\
\hline 34 & $30 \mathrm{~F}$ & $\mathbf{L}$ & 6 & 46 & Unknown & 3NP, RHB, RD & 43 \\
\hline 35 & $31 \mathrm{M}$ & $\mathbf{R}$ & 4 & 46 & Ceased & CRN (2) & 22 \\
\hline 36 & $31 \mathrm{M}$ & $\mathbf{R}$ & 10 & 65 & Ceased & CVN (3) & 24 \\
\hline 37 & $31 \mathrm{~F}$ & $\mathbf{L}$ & 3 & 53 & Ceased & 3NP, CRN & - \\
\hline 38 & $32 \mathrm{M}$ & $\mathbf{L}$ & 8 & 65 & Improved & PRH, VH (3), PVD, CVN & 37 \\
\hline 39 & $33 \mathrm{M}$ & $\mathbf{R}$ & 3 & 36 & Ceased & Nil & - \\
\hline 40 & $35 \mathrm{~F}$ & $\mathbf{L}$ & 3 & 65 & Ceased & CVN & 41 \\
\hline 41 & $36 \mathrm{M}$ & $\mathbf{R}$ & 2 & 19 & Improved & VRT, ERM & - \\
\hline 42 & $37 \mathrm{M}$ & L & 6 & 36 & Improved & $3 N P$ & - \\
\hline 43 & $38 \mathrm{~F}$ & $\overline{\mathbf{R}}$ & 4 & 53 & Improved & RHB, VH & - \\
\hline 44 & $40 \mathrm{~F}$ & $\mathbf{R}$ & 1 & 65 & Improved & RHB, CVN & 21 \\
\hline 45 & $41 \mathrm{M}$ & $\mathbf{R}$ & 4 & 9 & Ceased & Nil & - \\
\hline 46 & $50 \mathrm{M}$ & $\mathbf{R}$ & 4 & 17 & Ceased & Nil & - \\
\hline 47 & $51 \mathrm{M}$ & $\mathbf{R}$ & 8 & 65 & Ceased & CRN & 39 \\
\hline 48 & $51 \mathrm{~F}$ & $\mathbf{L}$ & 6 & 65 & Ceased & Nil & 19 \\
\hline 49 & $55 \mathrm{~F}$ & $\vec{L}$ & 1 & 36 & Ceased & $\mathrm{Nil}$ & - \\
\hline 50 & $62 \mathrm{~F}$ & $\mathbf{R}$ & 2 & 65 & Ceased & Nil & 18 \\
\hline 51 & $64 \mathrm{M}$ & $\mathbf{L}$ & 3 & 53 & No change & $\mathrm{Nil}$ & - \\
\hline \multicolumn{8}{|c|}{ Sickle cell $-\beta^{+}$thalassaemia } \\
\hline 52 & $19 \mathrm{M}$ & $\mathbf{R}$ & 2 & 65 & Ceased & PRH, CVN & 33 \\
\hline 53 & $29 \mathrm{M}$ & $\mathbf{L}$ & 3 (D) & 65 & Ceased & AU, PRH (5), CRN & 12 \\
\hline 54 & $39 \mathrm{~F}$ & $\mathbf{R}$ & 1 & 53 & Ceased & CRN & - \\
\hline 55 & $62 M$ & $\mathbf{L}$ & 4 & 65 & Ceased & CRN & 40 \\
\hline \multicolumn{8}{|c|}{ Sickle cell- $\beta^{\circ}$ thalassaemia } \\
\hline 56 & $27 \mathrm{M}$ & $\mathbf{L}$ & 5 & 65 & Ceased & 3NP, CRN & 31 \\
\hline 57 & $34 \mathrm{M}$ & $\mathbf{L}$ & 3 & 46 & Ceased & 3NP, CVN & 32 \\
\hline
\end{tabular}

Age indicates age on admission to study.

Complications: $3 \mathrm{NP}=$ Partial third nerve palsy. AU $=$ Anterior uveitis. ASI $=$ Anterior segment ischaemia. RHB $=$ Retinal haemorrhage confined to coagulation lesion. PRH $=$ Preretinal haemorrhage. VH $=$ Vitreous haemorrhage. VRT $=$ Vitreoretinal traction. PVD $=$ Posterior vitreous detachment associated with vitreoretinal traction. ERM $=$ Epiretinal membrane. $R T=R e t i n a l$ tear. $R D=R e t i n a l$ detachment. CRN = Choroidoretinal neovascularisation. $\mathrm{CVN}=$ Choroidovitreal neovascularisation. $(\mathrm{n})=\mathrm{n}$ as suffix indicates number of lesions. 
Table 2 Visual acuity measured on first and last attendance in treatment and control eyes, with probable cause of decreased acuity

\begin{tabular}{|c|c|c|c|c|c|c|c|}
\hline \multirow{3}{*}{ Genotype } & \multirow{3}{*}{$\begin{array}{l}\text { Patient } \\
\text { no. }\end{array}$} & \multirow{3}{*}{$\begin{array}{l}\text { Eye } \\
\text { treated }\end{array}$} & \multicolumn{4}{|c|}{ Visual acuity } & \multirow{3}{*}{$\begin{array}{l}\text { Cause of decreased } \\
\text { acuity in treatment } \\
\text { (comparison) eye }\end{array}$} \\
\hline & & & \multicolumn{2}{|c|}{ Treatment eye } & \multicolumn{2}{|c|}{ Comparison eye } & \\
\hline & & & Start & End & Start & End & \\
\hline SS & $\begin{array}{l}1 \\
2 \\
3 \\
4 \\
5 \\
6 \\
7 \\
8\end{array}$ & $\begin{array}{l}\mathbf{L} \\
\mathbf{L} \\
\mathbf{R} \\
\mathbf{L} \\
\mathbf{R} \\
\mathbf{L} \\
\mathbf{R} \\
\mathbf{R}\end{array}$ & $\begin{array}{l}6 / 6 \\
6 / 6 \\
6 / 9 \\
6 / 18 \\
6 / 6 \\
6 / 6 \\
6 / 6 \\
6 / 12\end{array}$ & $\begin{array}{l}6 / 6 \\
6 / 6 \\
6 / 9 \\
6 / 18 \\
6 / 9 \\
6 / 6 \\
6 / 12 * \\
6 / 24\end{array}$ & $\begin{array}{l}6 / 6 \\
6 / 6 \\
6 / 9 \\
6 / 6 \\
6 / 6 \\
6 / 6 \\
6 / 60 \\
\text { NPL }\end{array}$ & $\begin{array}{l}6 / 6 \\
6 / 6 \\
6 / 9 \\
6 / 12 * \\
6 / 12 * \\
6 / 6 \\
6 / 24 \\
\text { NPL }\end{array}$ & $\begin{array}{l}\text { (Unknown) } \\
\text { (Unknown) } \\
\text { Unknown, (ERM) } \\
\text { VH, (phthisis bulbi) }\end{array}$ \\
\hline SC & $\begin{array}{l}9 \\
10 \\
11 \\
12 \\
13 \\
14 \\
15 \\
16 \\
17 \\
18 \\
19 \\
20 \\
21 \\
22 \\
23 \\
24 \\
25 \\
26 \\
27 \\
28 \\
29 \\
30 \\
31 \\
32 \\
33 \\
34 \\
35 \\
36 \\
37 \\
38 \\
39 \\
40 \\
41 \\
42 \\
43 \\
44 \\
45 \\
46 \\
48 \\
49 \\
50 \\
51\end{array}$ & $\begin{array}{l}\mathbf{R} \\
\mathbf{R} \\
\mathbf{L} \\
\mathbf{R} \\
\mathbf{L} \\
\mathbf{L} \\
\mathbf{R} \\
\mathbf{R} \\
\mathbf{L} \\
\mathbf{L} \\
\mathbf{L} \\
\mathbf{L} \\
\mathbf{R} \\
\mathbf{L} \\
\mathbf{R} \\
\mathbf{R} \\
\mathbf{R} \\
\mathbf{R} \\
\mathbf{R} \\
\mathbf{L} \\
\mathbf{R} \\
\mathbf{L} \\
\mathbf{L} \\
\mathbf{L} \\
\mathbf{R} \\
\mathbf{L} \\
\mathbf{R} \\
\mathbf{R} \\
\mathbf{L} \\
\mathbf{L} \\
\mathbf{R} \\
\mathbf{L} \\
\mathbf{R} \\
\mathbf{L} \\
\mathbf{R} \\
\mathbf{R} \\
\mathbf{R} \\
\mathbf{R} \\
\mathbf{R} \\
\mathbf{L} \\
\mathbf{L} \\
\mathbf{R} \\
\mathbf{L}\end{array}$ & 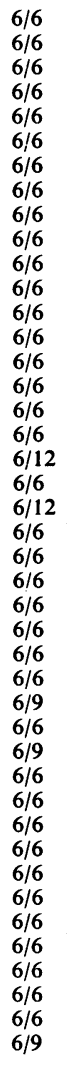 & $\begin{array}{l}6 / 6 \\
6 / 6 \\
6 / 6 \\
6 / 6 \\
6 / 6 \\
6 / 6 \\
6 / 6 \\
6 / 6 \\
6 / 6 \\
6 / 6 \\
6 / 12^{*} \\
6 / 12^{*} \\
6 / 6 \\
6 / 12^{*} \\
6 / 6 \\
6 / 18^{* *} \\
6 / 6 \\
<6 / 60^{* *} \\
6 / 6 \\
6 / 6 \\
6 / 18 \\
6 / 6 \\
6 / 6 \\
6 / 6 \\
6 / 6 \\
<6 / 60^{* *} \\
6 / 6 \\
6 / 60^{* *} \\
6 / 9 \\
6 / 18^{* *} \\
6 / 6 \\
6 / 6 \\
6 / 9 \\
6 / 6 \\
6 / 9 \\
6 / 6 \\
? \\
6 / 6 \\
6 / 9 \\
6 / 6 \\
6 / 6 \\
6 / 6 \\
6 / 18^{*}\end{array}$ & $\begin{array}{l}\text { 6/6 } \\
\text { No PSR } \\
\text { No PSR } \\
6 / 6 \\
6 / 6 \\
6 / 6 \\
6 / 6 \\
6 / 6 \\
6 / 6 \\
\text { No PSR } \\
\text { No PSR } \\
6 / 6 \\
6 / 6 \\
\text { CF } \\
\text { No PSR } \\
6 / 6 \\
6 / 24 \\
6 / 6 \\
\text { No PSR } \\
6 / 6 \\
6 / 6 \\
6 / 6 \\
\text { No PSR } \\
6 / 6 \\
6 / 6 \\
6 / 6 \\
\text { NPL } \\
6 / 36 \\
6 / 9 \\
6 / 12 \\
6 / 6 \\
6 / 6 \\
\text { NPL } \\
6 / 6 \\
6 / 6 \\
6 / 6 \\
6 / 6 \\
6 / 6 \\
6 / 6 \\
66 / 60 \\
\text { No PSR } \\
6 / 6 \\
6 / 9 \\
6\end{array}$ & $\begin{array}{l}6 / 6 \\
\\
6 / 6 \\
6 / 6 \\
6 / 6 \\
6 / 6 \\
6 / 6 \\
6 / 6 \\
\\
6 / 9 \\
6 / 6 \\
\text { CF } \\
6 / 6 \\
6 / 24 \\
6 / 6 \\
6 / 6 \\
6 / 6 \\
6 / 6 \\
6 / 6 \\
6 / 6 \\
6 / 6 \\
\text { NPL } \\
6 / 60 \\
6 / 9 \\
6 / 60 * * \\
6 / 6 \\
6 / 6 \\
\text { NPL } \\
6 / 6 \\
6 / 6 \\
6 / 9 \\
? \\
6 / 6 \\
6 / 9 \\
<6 / 60 \\
6 / 6 \\
6 / 36 * *\end{array}$ & $\begin{array}{l}\text { VH } \\
\text { Unknown } \\
\text { ERM (VO) } \\
\text { VO } \\
\text { RD } \\
\text { RD } \\
\text { (RD) } \\
\text { ? Macular oedema (RD) } \\
\text { Bilateral VH } \\
\text { (Phthisis bulbi) } \\
\text { Cataract (VH) } \\
\text { (Choroidal ischaemia) }\end{array}$ \\
\hline $\mathbf{S} \beta+$ thal & $\begin{array}{l}52 \\
53 \\
54 \\
55\end{array}$ & $\begin{array}{l}\mathbf{R} \\
\mathbf{L} \\
\mathbf{R} \\
\mathbf{L}\end{array}$ & $\begin{array}{l}6 / 6 \\
6 / 6 \\
6 / 6 \\
6 / 6\end{array}$ & $\begin{array}{l}6 / 9 \\
6 / 12 * \\
6 / 6 \\
6 / 6\end{array}$ & $\begin{array}{l}6 / 6 \\
6 / 6 \\
\text { No PSR } \\
\text { No PSR }\end{array}$ & $\begin{array}{l}6 / 9 \\
6 / 6\end{array}$ & Unknown \\
\hline$S \beta^{\circ}$ thal & $\begin{array}{l}56 \\
57\end{array}$ & $\begin{array}{l}\mathbf{L} \\
\mathbf{L}\end{array}$ & $\begin{array}{l}6 / 6 \\
6 / 6\end{array}$ & $\begin{array}{l}6 / 6 \\
6 / 6\end{array}$ & $\begin{array}{l}6 / 6 \\
6 / 6\end{array}$ & $\begin{array}{l}6 / 6 \\
6 / 6\end{array}$ & \\
\hline
\end{tabular}

*Deterioration in visual acuity of 2 lines or more and ** of 3 lines or more.

Abbreviations as in Table 1 except NPL $=$ no perception of light; $C F=$ counting fingers; VO $=$ vitreous organisation 

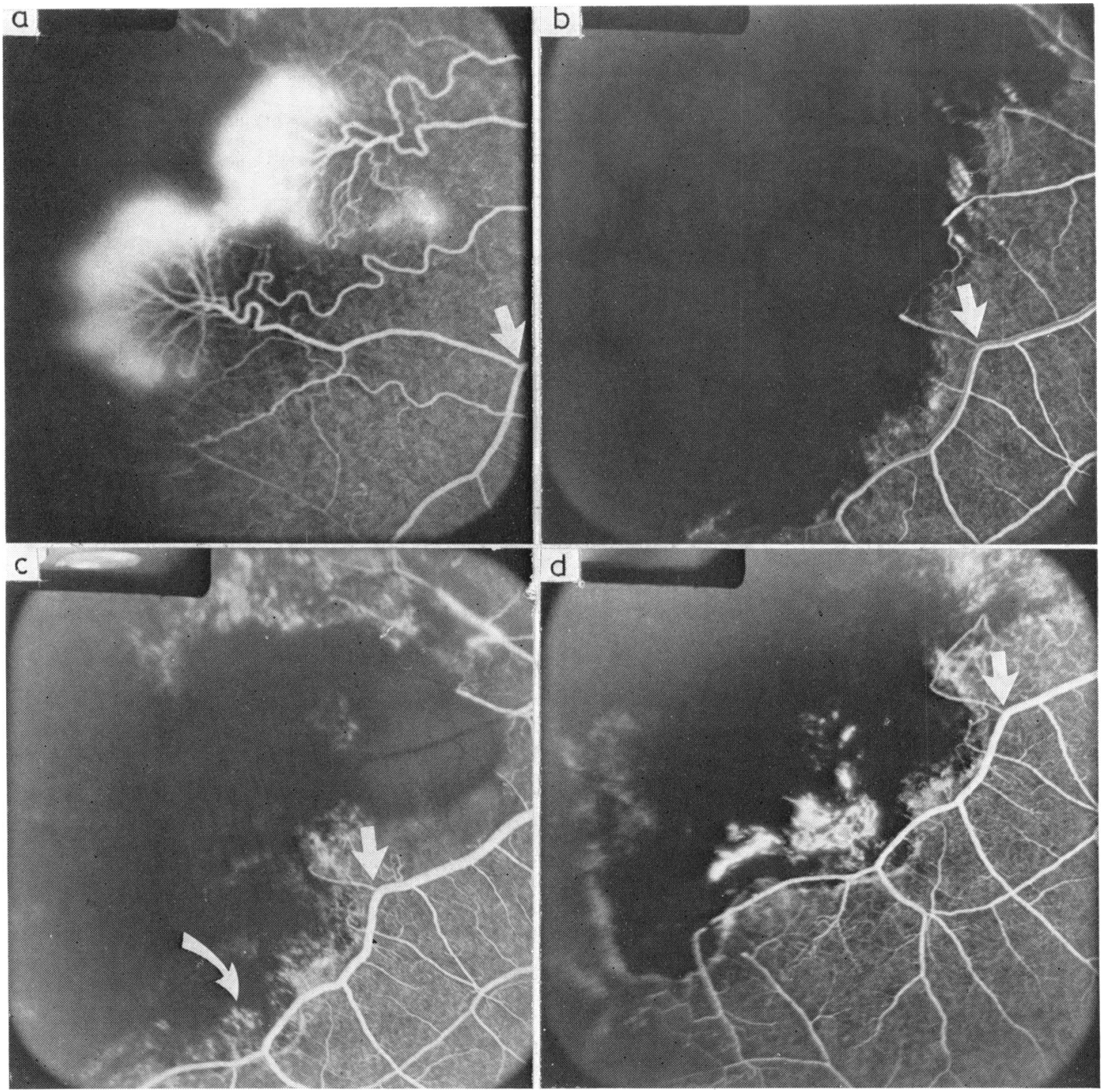

Fig. 2 Fluorescein angiograms demonstrating development of choroidoretinal neovascularisation in the right temporal area of a 27-year-old female with SC disease (case 27): same vessel junction marked by straight arrow. (a) Initial PSR lesion. (b) Two weeks after photocoagulation. (c) Nine months post treatment-major choroidal vessels visible and indicated by curved arrow. (d) Sixteen months post treatment-choroidoretinal neovascularisation.

34) and one who was pregnant (case 15). In the remaining 54 patients leakage from the originally treated PSR lesion was considered to have ceased in $44(81 \%)$, improved in $8(15 \%)$, and persisted unchanged in $2(4 \%)$.

\section{CHOROIDAL NEOVASCULARISATION}

In 31 patients fluorescein leakage subsequently developed at the site of photocoagulation, all of which showed fine vessel systems within the burn area apparently supplied by choroidal vessels and draining through either choroidal or retinal veins. In 19 patients these abnormal vessels were in the plane of the retina, and their fluorescence was separated from the surrounding normally perfused retina by a margin of nonfluorescence. These lesions were referred to as choroidoretinal neovascularisation (CRN), and an example is illustrated in Fig. 2. 


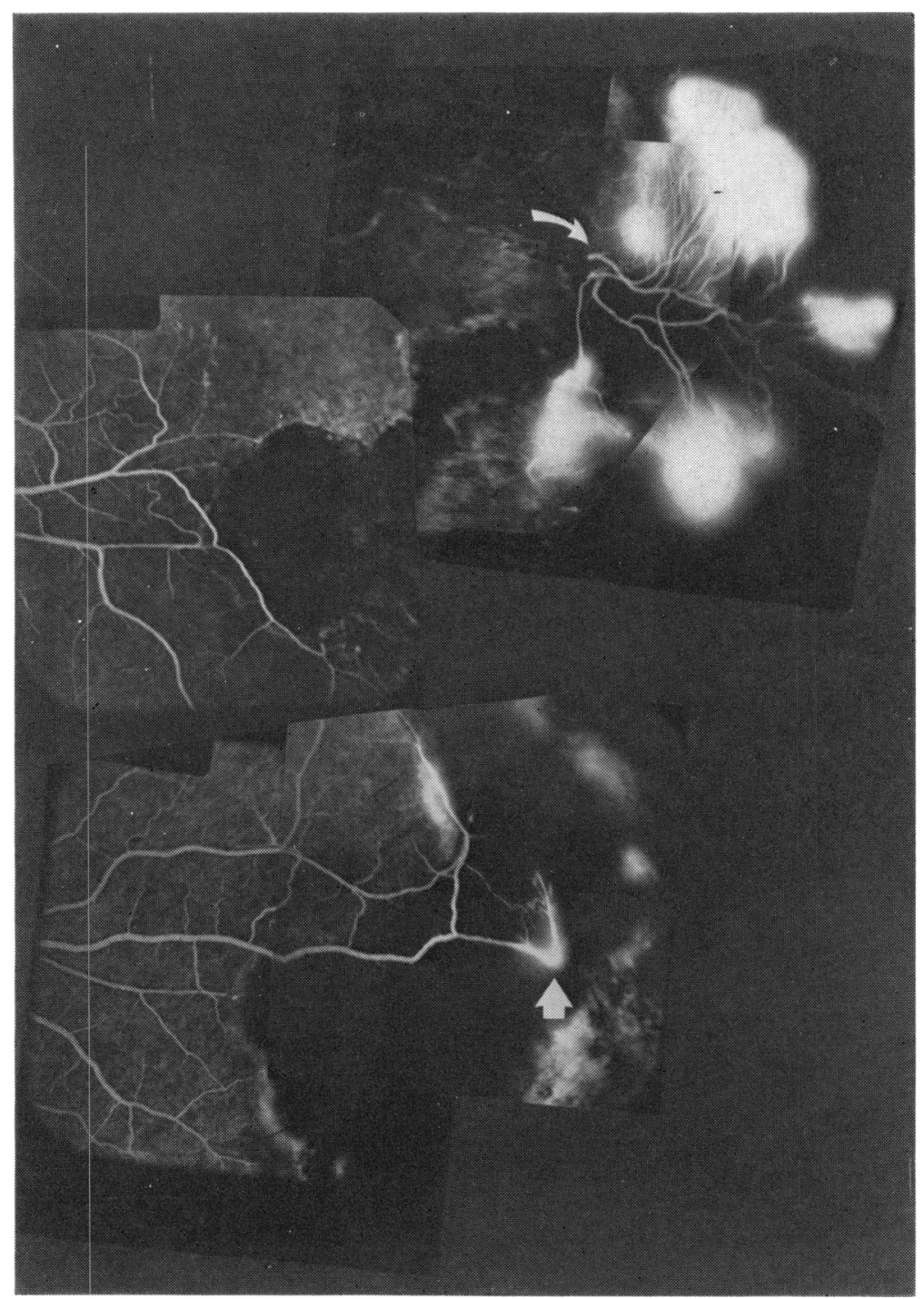

Fig. 3 Composite fluorescein angiogram depicting choroidovitreal neovascularisation in the left temporal area of a 25-yearold female with $S C$ disease (case 22) 28 months after photocoagulation. Lower arrow indicates coagulation site of principal feeder vessels for large PSR lesion. Upper arrow indicates site of choriovitreal neovascularisation.

In 12 patients the abnormal vessel system projected into the vitreous, and fluorescence from these lesions frequently overlay normal retina. These lesions were referred to as choroidovitreal neovascularisation $(\mathrm{CVN})$, and an example is illustrated in Fig. 3. Four of the CVN lesions developed from CRN lesions during the period of follow-up, 2 apparently spontaneously and 2 after therapy of the CRN lesion. The remaining CRN lesions remained flat for follow-up periods of up to 54 months, did not enlarge, and did not give rise to complications. Choroidovitreal neovascularisation, however, underwent rapid enlargement in 5 patients (cases 11, $19,22,28,33)$ and was associated with vitreous haemorrhage in four (cases $10,11,19,38$ ). Photocoagulation of CRN lesions in 9 patients stopped fluorescein leakage in 3 (cases $20,25,35$ ) and of CVN lesions in 7 patients stopped leakage in 1 (case 10).

\section{HAEMORRHAGE}

Preretinal haemorrhages occurred in 6 patients and were multiple in 3 patients, all of whom had received diathermy. Three patients (cases 20, 24, 53) developed haemorrhages in direct relationship to the diathermy burns, and two of these also developed preretinal haemorrhages in remote areas of the same eye. Two patients (cases 11,52 ) developed 
preretinal haemorrhages in relation to $\mathrm{CVN}$ lesions 4 years after therapy, and 1 patient (case 38) developed two preretinal haemorrhages, one as an extension of a deep retinal haemorrhage, 16 and 26 months after therapy. Retinal haemorrhage confined to the burn area occurred in 9 patients. Neither form of haemorrhage extended into the vitreous or affected visual acuity. Vitreous haemorrhage occurred in the treatment eye in 8 patients, 4 of whom had choroidovitreal neovascularisation. In 1 of these (case 10) a limited vitreous haemorrhage occurred during photocoagulation of a CVN lesion, but in the remainder the haemorrhage occurred $1 \frac{1}{2}-3$ years after therapy.

\section{VITREORETINAL TRACTION}

Vitreoretinal traction developed or became worse during the study in 7 patients. In 2 patients it was associated with epiretinal membranes and in 4 with posterior vitreous detachments. A retinal tear produced during therapy in one patient (case 8) was successfully sealed by further light coagulation at the same treatment session. Retinal detachment occurred in 2 patients both having had retreatment for a persistently perfused PSR lesion. In one (case 26) photocoagulation of a darkly pigmented area produced excessive heat release, with fracture of Bruch's membrane and an immediate subretinal haemorrhage which spread to the vitreous. This did not change for 1 month, but 4 months later a gradual blurring of vision occurred, and examination 1 year after the original treatment revealed no red reflex, no observable detail behind the lens, and inaccurate projection of light. The other patient (case 34) had apparently uneventful initial therapy but noted progressive deterioration of vision 1 year later, and examination 3 years after this revealed gross vitreoretinal traction and a total retinal detachment, which was unsuccessfully repaired with vitreoretinal surgery.

\section{OTHER COMPLICATIONS OF THERAPY}

Other complications in the treatment group included anterior uveitis, anterior segment ischaemia, partial third nerve palsies, haemorrhage, vitreoretinal changes, and retinal detachment.

Anterior uveitis occurred in 4 patients and settled promptly on systemic and topical steroid therapy. Anterior segment ischaemia occurred in 1 patient after scleral diathermy despite care being taken to avoid the long ciliary vessels or detachment of ocular muscles. This complication gradually settled on systemic and topical steroids, but signs of iris atrophy, irregularity of the pupil, and extensive anterior and posterior synechiae remained. Both anterior uveitis and anterior segment ischaemia were confined to patients treated by scleral diathermy and were not considered complications of photocoagulation.

Partial third nerve palsies followed retrobulbar injection of local anaesthetic in 7 patients, all resolving satisfactorily within 2-3 weeks. There was the clinical impression that this complication was more common in patients requiring larger volumes of anaesthetic for effective anaesthesia.

BEHAVIOUR OF COMPARISON EYE GROUP Of the 47 comparison eyes gross pathology precluded satisfactory longitudinal observations on PSR in 6. Four had retinal detachment (cases 8, $35,36,41$ ) and 1 gross vitreous fibrosis (case 22) on admission to the study, and 1 patient (case 5) developed a gross vitreous haemorrhage after initial examination. Of the remaining 41 eyes 10 developed PSR for the first time during the study period, and an increase in the number or size of PSR lesions occurred in a further 21 patients. Autoinfarcted PSR lesions were present on admission to the study in 6 patients and developed during the study in 16, three showing complete autoinfarction of all leaking lesions and 13 a combination of autoinfarction and progression. When angiographic assessments were compared at the beginning and end of the study in the 41 comparison eyes with adequate data, 25 $(60 \%)$ indicated more extensive perfused PSR, 8 $(20 \%)$ showed no change, and $8(20 \%)$ improved. In 3 of the latter patients PSR developed and spontaneously infarcted during the study period. The comparison group showed preretinal haemorrhages in 3 eyes and vitreous haemorrhages in 7 eyes. One vitreous haemorrhage (case 5) followed trauma to an eye with perfused PSR, the significance of which was difficult to assess.

Visual acuity, measured at the first and last attendance during the study, decreased by 2 lines or more on the Snellen chart in $12 / 57(21 \%)$ of the treatment group compared to $4 / 42(10 \%)$ of the comparison group. Deterioration of 3 lines or more occurred in $5(9 \%)$ and $2(5 \%)$ respectively and was attributed in the treatment group to retinal detachment (2), vitreous organisation (1), vitreous haemorrhage (1), and possible macular oedema (1), and in the comparison group to vitreous haemorrhage (2). The visual acuity in 1 patient in the treatment group (case 36) attributed to possible macular oedema subsequently improved to $6 / 12$.

\section{Discussion}

The abnormal vessel systems that develop at the junction of vascular and avascular retina in sickle cell disease may compromise vision by causing 
vitreous haemorrhage and/or retinal detachment. Rendering these lesions avascular appears logical, and their characteristic anatomy, with feeding arterioles and draining veins, makes them amenable to closure by localised coagulation. Xenon arc, argon laser, diathermy, and cryopexy have been employed, the present study using the xenon arc with supplemental diathermy in some cases. The procedure included coagulation of the feeding arterioles after their identification by fluorescein angiography, followed by coagulation of the proliferative lesion. Coagulation of the veins was not performed. The method and details of treatment of 33 patients in this series have been previously published. ${ }^{2}$

These methods are capable of stopping perfusion in most proliferative lesions. Condon and Serjeant ${ }^{2}$ achieved closure in $91 \%$ of 36 eyes treated with predominantly xenon arc and Goldbaum et $a .^{3}$ reported similar results in 53 eyes using either xenon or argon photocoagulation. However, the follow-up periods in these studies were relatively short, ranging from 2 weeks to $2 \frac{1}{2}$ years. The initial closure rate of $87 \%$ in the present study is similar to that in earlier series, 3 patients continuing to leak despite repeated photocoagulation.

The development of fluorescein leakage from vessel networks developing within the burn area complicated angiographic assessment of continued closure during follow-up. Noted initially as 'spot leakage' within the photocoagulation scar, fine networks of vessels developed, fed from the choroidal vessels and draining into either the retinal or choroidal veins. Two patterns of this choroidal neovascularisation were apparent. The term choroidoretinal neovascularisation (CRN) was used to describe vessel systems which lay flat in the plane of the retina and was not intended to imply anastomoses between choroidal and retinal circulations, although they frequently occurred. These lesions produced fluorescence within the burn area, which was usually separated by a margin of nonfluorescence from surrounding normally perfused retina. This abnormality has not been previously reported but has been noted elsewhere (Dr Lee Jampol, personal communication). Throughout follow-up periods up to 54 months these abnormal vessels generally did not enlarge or give rise to complications. The term choroidovitreal neovascularisation (CVN) was applied to vessel systems which invaded the vitreous and were originally reported as complications of argon laser therapy. ${ }^{5}$ The high prevalence of CVNs in the present study $(22 \%)$ indicates that this is also a common complication with the xenon arc. These lesions tended to show progressive enlargement, and the association with vitreous haemorrhage in 4 patients suggested that their natural history may be less benign than that of the CRN. Further coagulation therapy of these lesions was attempted in 7 patients, successfully stopping perfusion in 1 , and it was interesting to note that rapid vitreous extension of a CVN in 1 patient was associated with decreased dye leakage compatible with spontaneous autoinfarction.

The aetiology of these lesions is unclear, though presumably related to breaks in Bruch's membrane caused by excessive energy release in the pigment epithelial layer. Reporting this complication following argon laser therapy, Goldbaum et al. ${ }^{3}$ attributed it to the high energy density associated with small $(50-100 \mu \mathrm{m})$ burn sizes and suggested that this complication did not occur with larger burns $(200-500 \mu \mathrm{m})$. These authors did not observe this complication with xenon arc therapy, in contrast to our own experience. Different techniques may have contributed to these different conclusions, Goldbaum et al. $^{3}$ limiting coagulation to the feeding vessels whereas the PSR lesion was also coagulated in the present study. Since on several occasions a small apparently innocuous PSR lesion was replaced, after therapy, by a larger potentially serious CVN, this complication must be avoided if xenon arc photocoagulation is to play a part in the management of PSR lesions in these patients.

Certain complications attended repeated photocoagulation. Increased organisation and rigidity of the vitreous body with subsequent traction on the internal limiting membrane of the retina of the posterior pole occurred in 7 patients, 6 of whom had had 2 or more treatment sessions. Posterior vitreous detachment occurred in 4 patients, but traction retinal detachment was not observed. In 1 patient with 4 treatment sessions gross vitreous fibrotic changes occurred with vitreoretinal traction and recurrent vitreous haemorrhages originating in the choroid or deep retina peripheral to the coagulated area. Retreatment of a darkly pigmented area in another resulted in retinal detachment and blindness. To diminish these dangers the minimally effective power of the coagulator should be used in retreatment of pigmented areas.

Other complications related to therapy included transient partial third nerve palsies, anterior uveitis and anterior segment ischaemia, and haemorrhages. The duration of burn with the xenon arc photocoagulator used (1.5-3.0 seconds), necessitated the routine use of retrobulbar anaesthesia. Partial third nerve palsies which developed in 7 patients were probably related to the volume or siting of retrobulbar injections and all resolved satisfactorily. Anterior uveitis and anterior segment ischaemia were confined to patients receiving diathermy and 
should probably not be considered complications of xenon arc photocoagulation. Multiple preretinal haemorrhages were also confined to the diathermy group. A single preretinal haemorrhage developed in 2 patients after xenon arc photocoagulation, but neither these nor the retinal haemorrhages confined to the burn area were of clinical significance.

Experience in the treated group must be compared with the behaviour of PSR in the comparison group during the study. Development or progression of PSR in 31 comparison eyes must be balanced against evidence of autoinfarction in 17 patients and complete cure in 3. Furthermore the rapid progression in some patients was not reflected in deteriorating visual acuity. There is some evidence that the most rapid progression of PSR occurs in the 15-30 year age group, ${ }^{9}$ which includes $27(47 \%)$ patients in the present study, and it is therefore possible that longer term follow-up will be associated with more complete regression of PSR.

In terms of visual acuity measured at the first and last attendance there was no significant difference between treatment and comparison groups over a mean 4-year follow-up period. In terms of vitreous haemorrhage an episode occurred in every 26.4 years of observation in the treatment group compared to 21.4 years of observation in the comparison group. However, the failure to demonstrate a difference between treatment and comparison groups must be treated with caution in view of the statistical limitations of the study. When the study was started in 1973, it was felt that the response to xenon arc photocoagulation in this condition was sufficiently unknown to justify treating only the worst affected eye. More data are now available, and if the problems of choroidal neovascularisation can be avoided there is a need for a proper randomly controlled trial of xenon arc therapy in PSR. With the realisation of the high prevalence of spontaneous autoinfarction, this study is especially necessary to define the role, if any, of photocoagulation in the therapy of these lesions.

\section{References}

1 Goldberg MF. Treatment of proliferative sickle retinopathy. Trans Am Acad Ophthalmol Otolaryngol 1971; 75: 532-56.

2 Condon PI, Serjeant GR. Photocoagulation and diathermy in the treatment of proliferative sickle retinopathy. $\mathrm{Br} J$ Ophthalmol 1974; 57: 650-62.

3 Goldbaum MH, Goldberg MF, Nagpal K, Asdourian GK, Galinos SO. Proliferative sickle retinopathy. In: L'Esperance FA, ed. Current Diagnosis and Management of Chorio-retinal Diseases. St Louis: Mosby, 1977: 132-45.

4 Goldberg MF, Acacio I. Argon laser photocoagulation of proliferative sickle retinopathy. Arch Ophthalmol 1973; 30: $35-44$.

5 Galinos SO, Asdourian GK, Woolf MB, Goldberg MF, Busse BJ. Choroido-vitreal neovascularisation after argon laser photocoagulation. Arch Ophthalmol 1975;93: 524-30.

6 Lee CB, Woolf MB, Galinos SO, Goldbaum MH, Stevens TS, Goldberg MF. Cryotherapy of proliferative sickle retinopathy. Part I. Single freeze-thaw cycle. Ann Ophthalmol 1975; 7: 1299-308.

7 Serjeant GR. The Clinical Features of Sickle Cell Disease. Amsterdam: North Holland, 1974: 59-62.

8 Condon PI, Serjeant GR. Ocular findings in hemoglobin SC disease in Jamaica. Am J Ophthalmol 1972; 74: 921-31.

9 Condon PI, Serjeant GR. The behaviour of untreated proliferative sickle retinopathy. $\mathrm{Br} J$ Ophthalmol 1980; 64: 404-11. 